\title{
The flow path characteristics analysis for supercritical carbon dioxide gas turbines
}

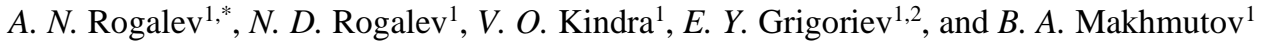 \\ ${ }^{1}$ National Research University "Moscow Power Engineering Institute", Moscow, Russia \\ ${ }^{2}$ Ivanovo State Power University named after V.I. Lenin, Ivanovo, Russia
}

\begin{abstract}
Rising carbon dioxide concentration in the atmosphere is probably the main reason of global warming. The development of the oxy-fuel combustion cycles is a possible way to decrease the energy sector contribution in the emission process. However, an unusual composition and thermodynamic parameters of the working fluid cause the necessity of revision of the main equipment characteristics, especially for the supercritical carbon dioxide gas turbine. This study presents the method and the results of the flow path preliminary analysis for the new generation gas turbines working on carbon dioxide. The flow path shape with a constant root diameter of seven stages was chosen as the most reasonable due to cheap manufacturing. Influence of reaction degree of stages and velocity ratio on stage geometric parameters are revealed. It was found that the optimal reaction degree and velocity ratio are equal to 0.25 and 0.36 correspondingly. Thermal and constructive stages characteristics of the $350 \mathrm{MW}$ turbine are determined.
\end{abstract}

\section{Introduction}

The results of the preliminary analysis contain turbine stages thermal and structural performance and form a base for the further detailed flow path design. Today turbine manufacturers meet new problems related to the new machine types with high technical and economic performance concerned to operation on untraditional fluids with supercritical parameters.

During the last decade, large efforts are spent on the development of the oxy-fuel combustion cycles with zero harmful emissions [1-5], and the NET Power cycle technology is one of the most prospective. The main operation component of the cycle is carbon dioxide. When burning natural gas, the cycle design efficiency may be up to $58.9 \%$ [6]. Nowadays this cycle is applied to a $50 \mathrm{MW}$ demonstration energy unit [7] developing in the USA.

The natural gas burning Allam cycle is shown in figure 1. Carbon dioxide is compressed to $80 \mathrm{bar}$ in a multi-stage inter-cooled compressor. Then a pump increases its pressure up to 300 bar. After this, the flow enriched with carbon dioxide enters the regenerator where it is heated to $700-750^{\circ} \mathrm{C}$ by turbine exhaust gas. Most of this gas is directed to the combustor as to limit the maximal temperature; a smaller part is supplied to gas turbine cooling. In the combustor, the working fluid heats up to $1150^{\circ} \mathrm{C}$. In the turbine flow path, the gas expands to $20-30$ bar pressure.

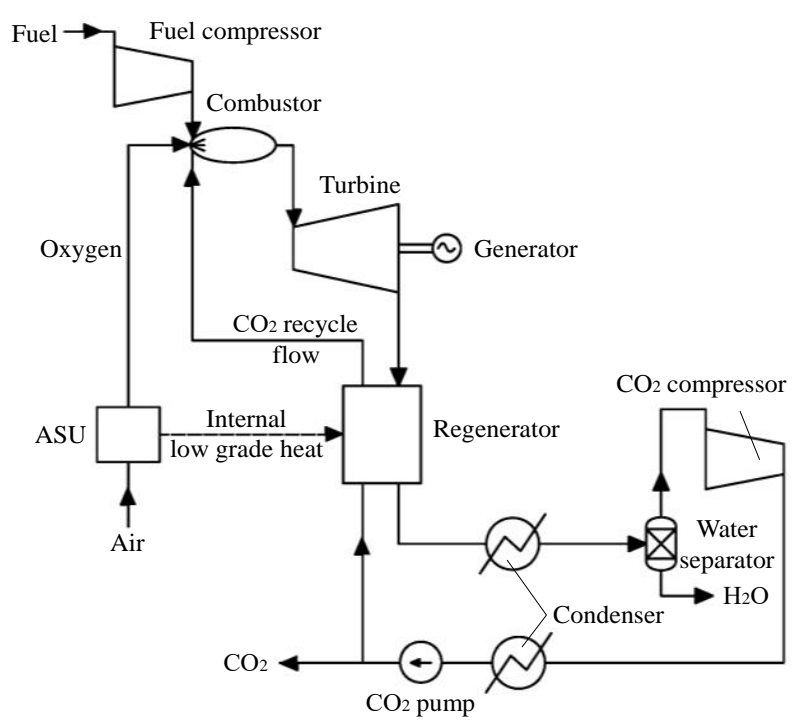

Fig. 1. Scheme of the Allam cycle.

On the contrary to traditional steam and gas turbines, the main Allam cycle flow content is carbon dioxide. Nevertheless, the initial pressure of 300 bar is typical for steam turbines and the initial temperature of $1150^{\circ} \mathrm{C}$ is widely used for gas turbines. Thus, it is reasonable to apply the existing background for the turbine design purpose.

The flow path preliminary analysis is a very important stage, the results of which give principal solutions that determine the machine mass, dimensions, technology, and financial performance. This paper proposes an algorithm for the supercritical carbon

\footnotetext{
* Corresponding author: r-andrey2007@yandex.ru
} 
dioxide preliminary flow path analysis. The algorithm involves specific experience for steam and gas turbine design and allows parametric studies for the turbine structural optimization.

The algorithm shows the main factors that determine the turbine stage dimensions. It may recommend the flow path shape, a number of stages, reaction degree and the velocity ratio $U / c_{s}$, where $U$ - circular velocity, $c_{s}-$ specific velocity..

\section{Turbo-machine design method}

The first stage of the preliminary design includes flow path shape selection. It allows identifying the turbine dimensions, technical and efficiency performance. The inlet parameters of the supercritical $\mathrm{CO}_{2}$ gas turbine determine small specific volumes about $0.01 \mathrm{~m}^{3} / \mathrm{kg}$ that influence dimensions of the first stages. It is desirable to use blades longer than $15 \mathrm{~mm}$ as to reduce the turbine cascade losses, first of all, the secondary losses [8-10]. Usually, this is achieved by reduction of the stage mean diameter. On the other side, the mean diameter decrease at high heat drops per stage leads to inefficient $U / c_{s}$ velocity ratios.

The steam turbine design experience shows that the small volumetric flow is a problem. The most reasonable flow path shape is the flow path with a constant blade root diameter $d_{\text {root. }}$ This shape is mostly used for highand intermediate-pressure steam turbines. Its main advantages are the following:

- Cheap manufacturing of rotor discs due to their constant diameters.

- Possibility to apply the "model stage" method when the stages are presented by shortening their tip parts, so the blades of all stages may have the same root couplings.

It is reasonable to design the supercritical carbon dioxide turbine using the existing background for highpressure steam turbines.

The preliminary flow path design with a constant root diameter consists of the dimensions calculation for the first, last and intermediate stages. The stage efficiency and its mean diameter are determined by the velocity ratio $U / c_{s}$. For reactive stages the optimal velocities ratio is defined as follows :

$$
\left(\frac{U}{c}\right)_{s} \approx \frac{\varphi \cdot \cos \alpha_{1}}{2 \cdot \sqrt{1-\rho}}
$$

where $\varphi$ represents the velocity coefficient of the vane row; $\alpha_{1}$ represents flow angle at the vane channel exit; $\rho$ represents the stage reaction degree.

Selection of the stages reaction degrees is an important step. Advanced steam turbines usually have a reaction degree from $5-10 \%$ in active type stages to 40 $50 \%$ in reactive stages $[11,12]$. For the gas turbines, the reaction degree is usually $20-25 \%$ [13].

Determination of the optimal values of reaction degree $\rho$, velocity ratio $U / c_{s}$ and the number of stages $n$ requires a feasibility study. On one hand, the reaction degree increase improves the blade flow conditions due to higher convergence factor, which is especially important for long blades. On the other hand, according to the equation (1) the reaction degree increase is followed by reduction of the optimal heat drop and an increase in the number of stages. Another option is stage diameter increase, related circular velocity increase and the first blades length reduction. More than that, the reaction degree growth increases the tip clearance leakages.

The first stage dimensions analysis includes parametric studies at different stage heat drops. It determines the main stage performance, blade length, root and mean diameters and the heat drop. Also the number of stages $n=z$ is preliminary determined. The plot solution for the first stage analysis is shown in figure 2 .

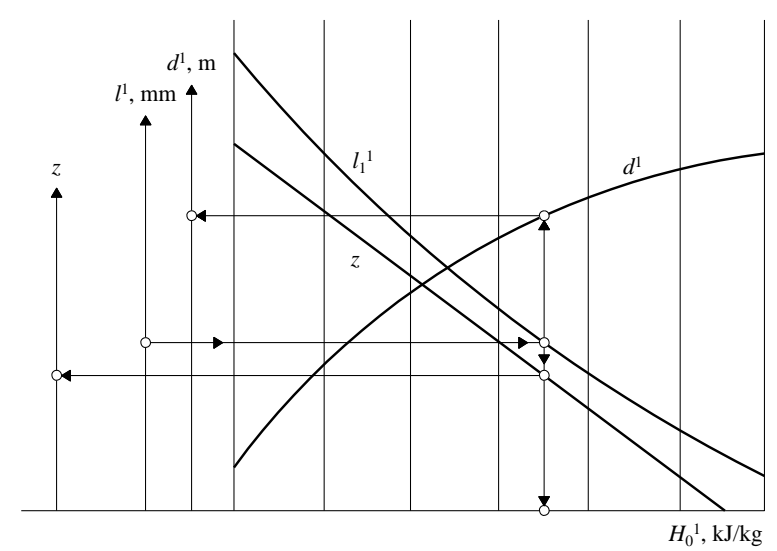

Fig. 2. Analysis of the first stage dimensions and the number of stages.

The last stage dimensions and its heat drop are determined by parametric studies at different values of its mean diameter. The last stage mean diameter $d^{z}$ mean is defined as follows:

$$
d_{\text {mean }}^{z}=a \cdot d_{\text {mean }}^{1},
$$

where $d_{1 \text { mean }}$ represents the first stage mean diameter; $a$ represents dimensionless coefficient varying from 1 to 1.3.

Then the intermediate stage performance is taken in a way to follow (3) that keeps the constant root diameter:

$$
d_{\text {root }}^{1}=d_{\text {root }}^{z}=\text { const. }
$$

A graphic solution for the last stages performance analysis is shown in figure 3 . 


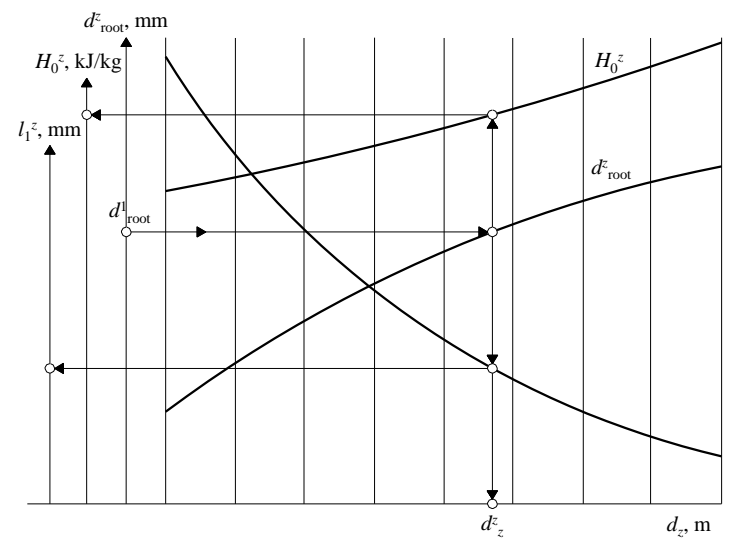

Fig. 3. Analysis of the last stage dimensions $\left(d_{\text {root }}=\right.$ const $)$.

\section{Implementation of the preliminary analysis algorithm}

Other intermediate stages parameters are determined by interpolation.

In the first iteration step, consideration of the heat return coefficient in the intermediate stages performance causes the unbalance of the stages heat drops sum and the available turbine heat drop $H_{0}$.

The unbalance may be eliminated by a change of stages number $(n=m)$ and re-calculation of the intermediate stages performance, or by the heat drops $H_{0 \mathrm{i}}$ correction at a constant number of stages $z$ and further re-evaluation of the stages performance in the next iteration step. In this paper, the unbalance was eliminated by the stage performance re-calculation at constant stages number $n=z$..

The algorithm of turbine flow path analysis described above was implemented for the parametric studies of supercritical carbon dioxide gas turbine. To identify carbon dioxide properties, the REFPROP 8.0 software was used.

\section{Flow path analysis results for the Allam cycle $350 \mathrm{MW}$ turbine}

The calculation input data are:

- Turbine inlet mass flow of $600 \mathrm{~kg} / \mathrm{s}$.

- Turbine inlet pressure of $30 \mathrm{MPa}$ and temperature of $1150^{\circ} \mathrm{C}$.

- Turbine outlet pressure of $3 \mathrm{MPa}$.

The inlet and outlet parameters produce available flow path heat drop of $650 \mathrm{~kJ} / \mathrm{kg}$.

As mentioned above the first step is the first stage performance analysis. It is possible to assume the stage reaction degree and the velocities ratio $U / c_{s}$ and to calculate the available stage heat drop. Selection of the parameters set is a combined technical and economic problem.

The example given in figure 4 shows the first turbine stage mean diameter distribution related to its heat drop at velocity ratio $U / c_{s}$ values from 0.3 to 0.5 and constant reaction degree $\rho=0.25$.

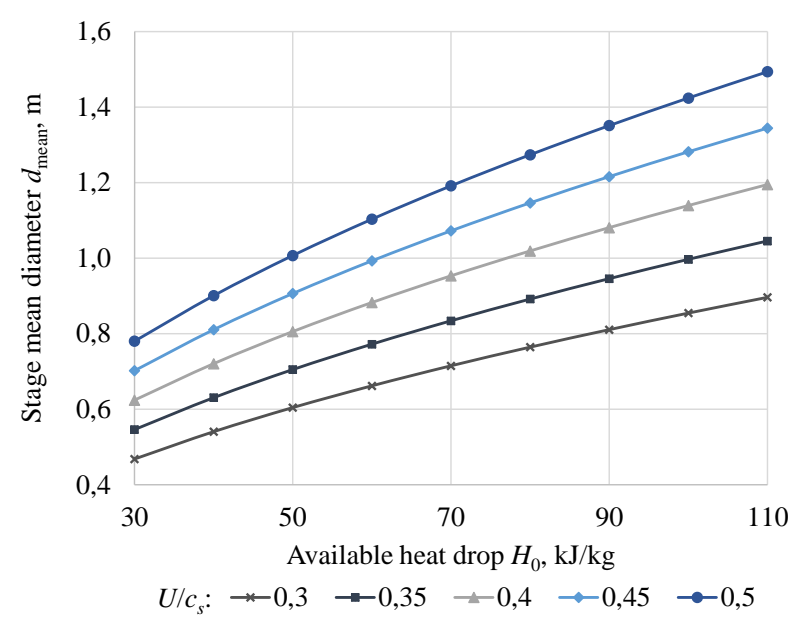

Fig. 4. Influence of the available stage heat drop on the stage mean diameter for the different velocity ratios $(\rho=0.25)$.

According to the equation (1) the optimal velocity ratio is equal to 0.5 for the reaction degree of 0.25 . However, if the constant heat drop is constant, the lower $U / c_{s}$ values, the lower the stage mean diameter. For example, the stage diameter for the velocity ratio equal to 0.5 is $1.5-2$ times higher than for the $U / c_{s}$ equal to 0.3 (figure 4). This effect allows optimization of the turbine metal consumption and envelope dimensions and this factor may be crucial when expensive heat resistant materials are used.

The number of turbine stages may be of similar importance. Figure 5 shows the turbine stages number depending upon the average heat drop per stage. The turbine compactness requirement provides a reasonable choice of the turbine number of stages below seven. Figure 5 shows the average heat drop above $80 \mathrm{~kJ} / \mathrm{kg}$.

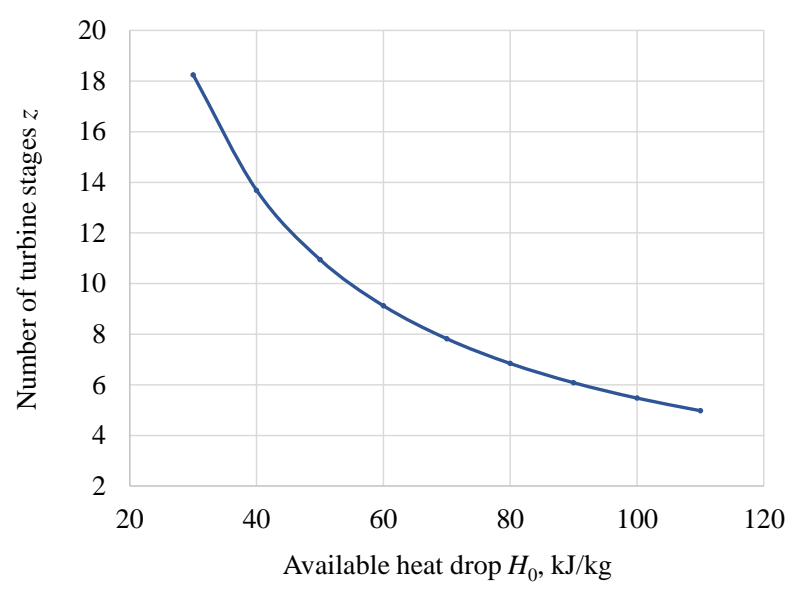

Fig. 5. Influence of the available stage heat drop on the number of turbine stages $(\rho=0.25)$.

Similar calculations with variable reaction degree allow optimization of the flow path. It is reasonable to analyze the reaction degree range of $0.05-0.25$ for active type stages and 0.5 for the reactive ones. The reaction degree mostly influences flow velocities in vane and blade rows, and the resulting flow path height, which may be seen in the mass flow equation. An example of the first vane length for the assumed turbine is shown in the figure 6 . 


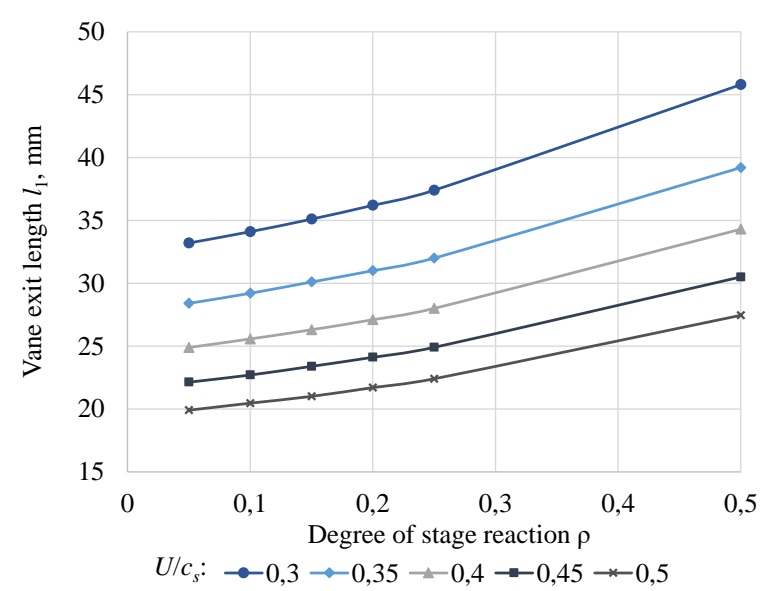

Fig. 6. Influence of the degree of stage reaction on the first vane exit length.

All reviewed versions satisfy the condition of the vane and blade minimal length above $15 \mathrm{~mm}$ but it is reasonable to use here the reaction degree below 0.25 . In reactive stages, the blade lengths are 20-25\% larger which requires more complicated cooling systems and higher coolant mass flow. Besides this, the optimal velocity ratio grows up to 0.68 , which leads to a larger stage diameter and a higher number of stages to reach an acceptable level of the internal turbine efficiency.

The analysis step of the first stage performance calculation determines the further turbine technical and economic performance. The results of the flow path optimization analysis for $350 \mathrm{MW}$ gas turbine are shown as a set of curves in figure 7 .

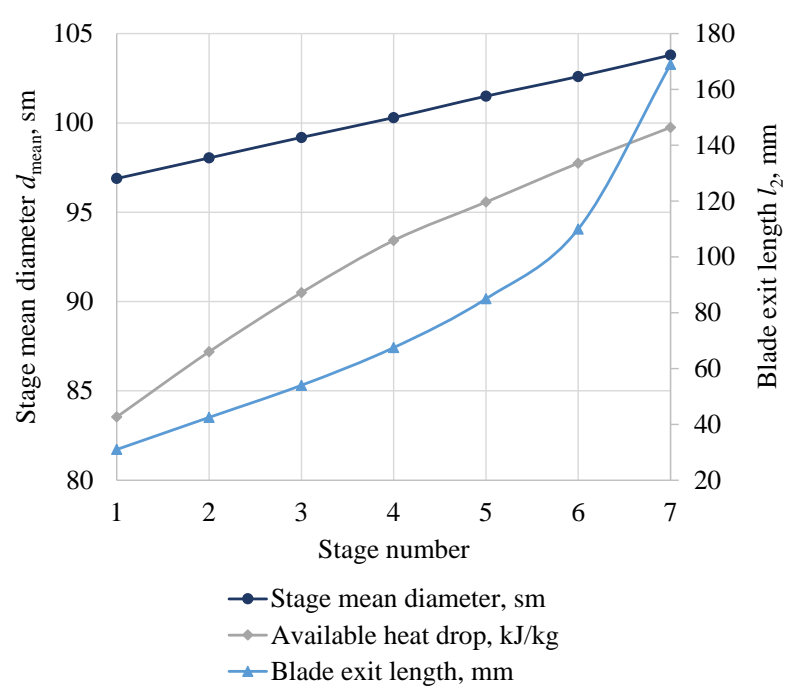

Fig. 7. The flow path preliminary design results for the supercritical carbon dioxide gas turbine of $350 \mathrm{MW}$ power.

The obtained stages diameters provide acceptable transversal envelope dimensions of the turbine, its exit diameter together with the housing thickness is about 2 $\mathrm{m}$. The design technology with the constant root diameter allows small fan factor of the last blade row and further detailed design of cylindrical turbine stages with the simplified "model stage" method. This allows blades configuration with shortened tip sections and standard types and dimensions of root coupling which finally results in cheaper turbine manufacturing. Besides this, the model stages application introduces standard solutions for the blade cooling.

The stage heat drop re-calculation required reduction of the velocities ratio $U / \mathcal{C}_{s}$ down to 0.36 , which allowed a constant number of seven stages. It is worth mentioning that in high power gas turbines the velocities ratio $U / c_{s}$ is within the $0.35-0.4$ range $[14,15]$.

\section{Conclusions}

A method for the preliminary design of supercritical carbon dioxide gas turbines for the Allam cycle has been developed and implemented.

Influence of reaction degree of stages and velocity ratio on stage geometric parameters are revealed.

Thermal and constructive stages characteristics of the 350 MW turbine are determined

This study conducted by National Research University "Moscow Power Engineering Institute" was supported by the Russian Science Foundation under Agreement No. 17-7920371 dated July 28, 2017.

\section{References}

[1] Oxy-combustion turbine power plants (Cheltenham: International Energy Agency) 636 (2015)

[2] A. Rogalev, V. Kindra, A. Zonov, N. Rogalev, L. Agamirov Evaluation of bleed flow precooling influence on the efficiency of the EMATIANT cycle Mechanics, Mechanical Engineering 22(2), 593-602 (2018)

[3] A.N. Rogalev, V.O. Kindra, N.D. Rogalev, V.P. Sokolov, I.A. Milukov, Methods for efficiency improvement of the semi-closed oxy-fuel combustion combined cycle J. Phys. Conf. Ser. 1111(1) 012003 (2018)

[4] H. Jericha, E. Göttlich, W. Sanz, F. Heitmeir Design optimisation of the Graz cycle prototype plant J. Eng. Gas Turbines Power 126(4), 733-740 (2004)

[5] M. Sammak, K. Jonshagen, M. Thern, Genrup, E. Thorbergsson, T. Grönstedt, A. Dahlquist Conceptual design of a mid-sized semi-closed oxy-fuel combustion combined cycle Proc. of the Turbine Technical Conf., Expo (Vancouver / ASME) (2011)

[6] R.J. Allam, M.R. Palmer, G.W. Brown Jr., J. Fetvedt, D. Freed, H. Nomoto, M. Itoh, N. Okita, C. Jones Jr. High efficiency, low cost of electricity generation from fossil fuels while eliminating atmospheric emissions, including carbon dioxide Energy Proced. 37, 1135-1149 (2013)

[7] Y. Iwai, M. Itoh, Y. Morisawa, S. Suzuki, D. Cusano, M. Harris Development approach to the combustor of gas turbine for oxy-fuel, supercritical CO2 cycle Proc. of the Turbine Technical Conf., Expo (Montreal / ASME) (2015)

[8] M.E. Deitch, G.A. Filippov Blade row aerodynamics (Moscow: Energoatomizdat) 240 (1996) 
[9] A. Zaryankin, A. Rogalev, S.Osipov, V. Kindra Supercritical carbon dioxide gas turbines for high-power generation AIP Conf. Proc. 2047(1) 020026 (2018)

[10] A. Rogalev, E. Grigoriev, V. Kindra, N. Rogalev Thermodynamic optimization and equipment development for a high efficient fossil fuel power plant with zero emissions J. Clean. Prod. 236117592 (2019)

[11] H.P. Bloch, M. Singh, M.P. Singh, Steam turbines (New York: McGraw-Hill Professional Publishing) 414 (2008)

[12] S. Havakechian, R. Greim, Aerodynamic design of 50 per cent reaction steam turbines I. Mech. Eng. C.-J. 213(1), 1-25 (1999)

[13] J.M. Tournier, M.S. El-Genk, Axial flow, multi-stage turbine and compressor models Energ. Convers. Manage. 51(1), 16-29 (2010)

[14] A.A. Inozemtsev, M.A. Nikhamkin, V.L. Sandratsky Basic design of aero engines and power units (Moscow: Mashinostroenie) 365 (2008)

[15] L. Moroz, Y. Govorushchenko, P. Pagur, A uniform approach to conceptual design of axial turbine/compressor flow path The Future of Gas Turbine Technology 3rd International Conf (Brussel) (2006) 